\title{
Development of Hybrid Composite Rice Husk Ash (RHA)-Geopolymer for Bricks Bearing Buildings
}

\author{
Andi Ikhsan Maulana ${ }^{1,2, *}$, Nurul Kusuma Wardani ${ }^{1,2}$, Syamsidar $\mathrm{D}^{1,2}$, Ariani $^{1}$, Nurfadilla ${ }^{1,2}$, \\ and Subaer ${ }^{1,2}$ \\ ${ }^{1}$ Material Physics Laboratory, FMIPA, Makassar State University, Makassar 90223, Indonesia \\ ${ }^{2}$ Konsorsium Riset Geopolimer Indonesia (KORIGI), Laboratorium Beton dan Bahan Bangunan, \\ Kampus ITS Sukolilo Surabaya, Indonesia, 6011
}

\begin{abstract}
The aim of this study is to synthesize hybrid composite rice husk ash (RHA)-geopolymer as materials for bricks bearing buildings application. Class-C fly ash was used as raw material and rice husk ash (RHA) taken directly from the field, washed and dried at $100^{\circ} \mathrm{C}$ for 4 hours. Geopolymers were synthesized through alkali activation method at $60^{\circ} \mathrm{C}$ for 1 hour with its molar oxide ration of $\mathrm{SiO}_{2} / \mathrm{Al}_{2} \mathrm{O}_{3}=3.0, \mathrm{Na}_{2} \mathrm{O} / \mathrm{SiO}_{2}=0.2$, and $\mathrm{H}_{2} \mathrm{O} / \mathrm{Na}_{2} \mathrm{O}=10$. There were three series of samples produced by mixing fly ash with addition of $5 \%, 10 \%$ and $15 \%$ RHA (relative to the mass of fly ash). The samples were tested after 7 days. The highest compressive strength were $26 \mathrm{MPa}$ which is reached by samples containing $10 \%$ RHA. The fire resistance measurement showed that the addition of RHA improved fire retardancy of geopolymers. The samples were immersed in $1 \mathrm{M} \mathrm{H}_{2} \mathrm{SO}_{4}$ solution for 4 days for acid resistance examination. The X-Ray Diffraction was performed to examine the chemical compositions of the samples before and after the test took place. Scanning Electron Microscopy (SEM) was performed to examine the morphology of these samples surfaces. The addition of $10 \%$ RHA in geopolymer showed its excellent properties in terms of mechanical strength, thermal properties, and acid resistance. The study suggests that hybrid composite RHA-geopolymer and can be developed as bricks bearing buildings.
\end{abstract}

\section{Introduction}

The advancement of material science and structural technology has fulfilled our needs on better and safer buildings. Nowadays, the main materials used for buildings or other structural products are bricks and Portland cement. Traditional bricks used for buildings normally have low mechanical strength, low heat, fire and strong chemical resistance. On the other hand, the needs to substitute the use of Portland cement have been increasing in recent decades. The production of Portland cement has been recognizing as one of the main contributor of greenhouse effect [1-3]. One of the promising environmentally friendly materials is geopolymers [4].

\footnotetext{
* Corresponding author: andi.ikhsan.maulana@gmail.com
} 
Geopolymer was first introduced by Davidovits in 1978 as inorganic polymers based on aluminosilicate minerals activated with alkali solution [4]. Geopolymers has been recognized as fire and acid resistant material, and show high early compressive strength similarly with Portland cement [2-6]. The excellent properties of geopolymers have placed these materials suitable to be used as structural materials [6]. Fly Ash (FA) has been used to produce geopolymers for many applications including concrete and bricks. FA produced by some coal-burning industries particularly in Indonesia is categorized as class-C. FA is an industrial waste rich with silica and alumina and its production is increasing every year causing serious environmental problems. Utilizing this waste as geopolymers precursor will turn FA from dangerous material into green and high quality material [1-2, 7-8].

Rice Husk Ash (RHA) is a one of the main source of silica $\left(\mathrm{SiO}_{2}\right)[4,9,10]$. This material is suitable to be used as fillers in the production of Portland cement or geopolymers. A mixture between RHA and FA will result in organic-inorganic hybrid composite [11]. The use of rice husk ash in bricks-making can provide several advantages such as improved compressive strength, reduce material costs, reduce environmental impact of waste materials, and reduce carbon dioxide emissions $[1,7,10]$.

Bearing bricks is a model of bricks preparation that can be locked to each other. This model can reduce the use of cement that binds the bricks in the cavity of the bricks. The advantage gained by this model are; (a) reducing the use of cement, (b) no building frame is needs. Figure 1 shows that the appearance of bricks. This brick has 3 holes on it and Figure 1c shows that these bricks bind by cement through the holes. There is one hole that not filled by cement. The function of the center hole is to reduce the heat transfer and to act as wave and vibration absorbance.

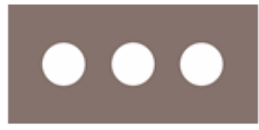

(a)

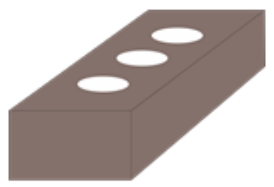

(b)

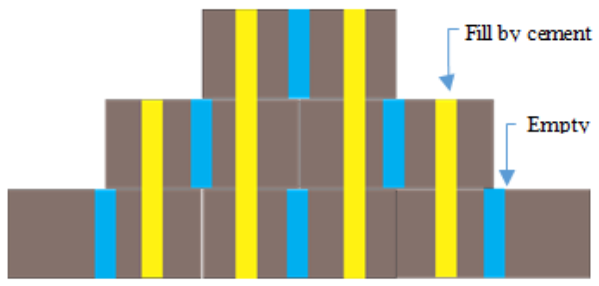

(c)

Fig. 1. Model of bricks: (a) from the top; (b) in 3D and (c) formation and cement filling

\section{Experimental}

This study is a development research that leads to the development of bricks bearing building model using class-C Fly Ash (FA) added with Rice Husk Ask (RHA) through alkali-activation method. RHA was washed and oven dried at $100^{\circ} \mathrm{C}$ for 4 hours. A mixture of sodium hydroxide $(\mathrm{NaOH})$, sodium silicate $\left(\mathrm{Na}_{2} \mathrm{O} .3 \mathrm{SiO}_{2}\right)$, and distilled water $\mathrm{H}_{2} \mathrm{O}$ with a certain concentration was used as an alkaline solution. Geopolymer was synthesized by mixing fly ash with variation of $5 \%, 10 \%$, and $15 \%$ RHA relative to the mass of fly ash.

Geopolymer paste was poured into the beam-shaped glass mold and then cured at $60^{\circ} \mathrm{C}$ for 1 hour. After the age of 24 hours, the samples were removed from the mold and tested after 7 days Mechanical properties of samples were performed to investigate its compressive strength. Thermal measurement was performed to investigate the resistance of samples ability from fire and heat. The chemical resistance of the samples was measured by immersing the sample into the sulphuric acid solution $\left(1 \mathrm{M} \mathrm{H}_{2} \mathrm{SO}_{4}\right)$ for 4 days. Samples which have been tested were chacterized by XRD to determine the compounds and 
crystalline structure. SEM-EDS to determine the morphological structure and its containing element of starting material and samples.

\section{Results and discussion}

Table 1 shows the magnitude of samples bulk density and apparent porosity measured by using Archimedes method. The magnitude of bulk density of the samples decrease as the content of RHA increase. Similarly, the apparent porosity also decreased as the RHA content increase. Similar result was reported by Safiuddin et. al. [12] who found that the porosity of their samples decrease as the the RHA content increase.

Table 1. The density and porosity of sample hybrid composite rice husk ash-geopolymer

\begin{tabular}{|c|c|c|}
\hline Sample & Density (g/cm & Porosity (\%) \\
\hline FA-ASP 5\% & 2.08 & 13.70 \\
\hline FA-ASP 10\% & 2.07 & 6.59 \\
\hline FA-ASP $15 \%$ & 2.03 & 6.16 \\
\hline
\end{tabular}

In this study, RHA is used as filler because it has high silica content. Fig. 2 shows the XRD characterization of rice husk ash with the highest peak lies between $17^{\circ}-20^{\circ}(2 \theta)$. The $\mathrm{XRD}$ analysis indicates that the main composition of were $\mathrm{SiO}_{2}(97 \mathrm{wt} \%)$ minerals in the form of tridymite and crystobalite, and $3 \mathrm{wt} \% \mathrm{TiO}_{2}$ (Rutile).

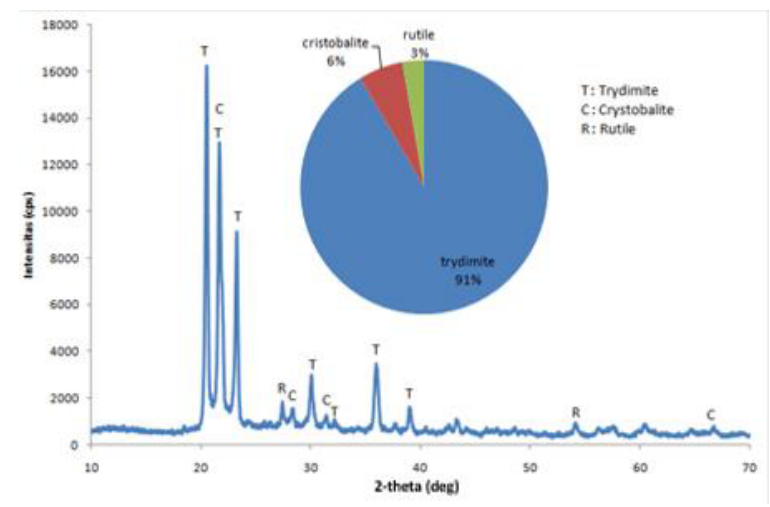

Fig. 2. X-Ray diffractogram of RHA

XRD diffractograms of fly ash as raw material shows the most dominant peak lies between $20^{\circ}-30^{\circ}(2 \theta)$ which consist of quartz, magnesium dialuminate, mullite, calcium peroxide and magnetite. The XRD pattern also shows that fly ash is a mixture of amorphous and crystalline phases. The main oxides in FA is quartz (32 wt \%) and magnetite (29 wt \%). 


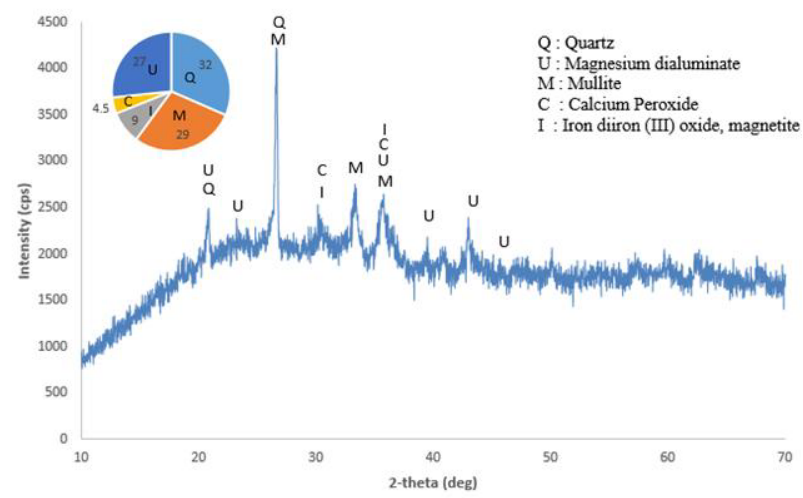

Fig. 3. X-Ray diffractogram of fly ash

Fig. 4 shows the diffraction pattern of three samples (with $5 \%, 10 \%$, and $15 \%$ variation of RHA) hybrid composite rice husk ash-geopolymer with the highest peak lies between $20^{\circ}$ $30^{\circ}(2 \theta)$. It shows that the addition of RHA can increase the peaks of trydimite and cristobalite.

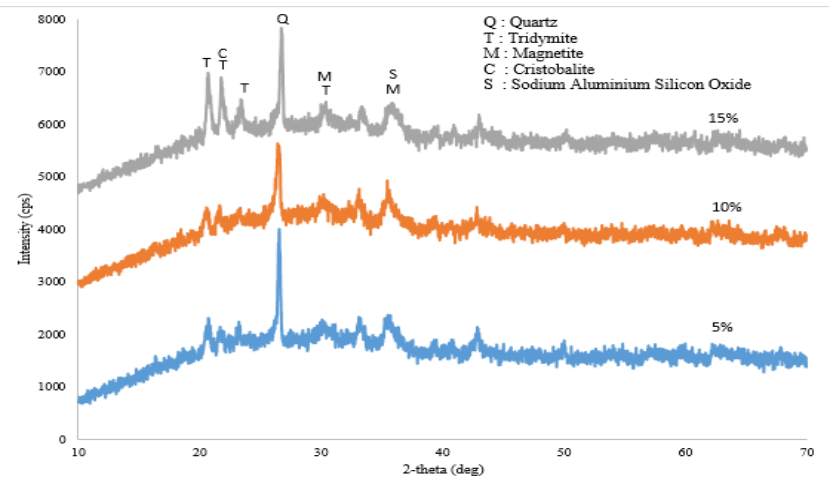

Fig. 4. X-Ray diffractogram of hybrid composite rice husk ash-geopolymer with RHA variation of 5\%, $10 \%$, and $15 \%$

Fig. 5 shows the morphology of the samples with addition of RHA. It can be seen that there are some FA and RHA particles which did not fully react in alkaline solutions. In addition, it was also found that micro-cracks appeared on the surface of the samples which is categorized as secondary cracks caused by polishing and vacuum during the preparation of the sample for SEM-EDS examination. 


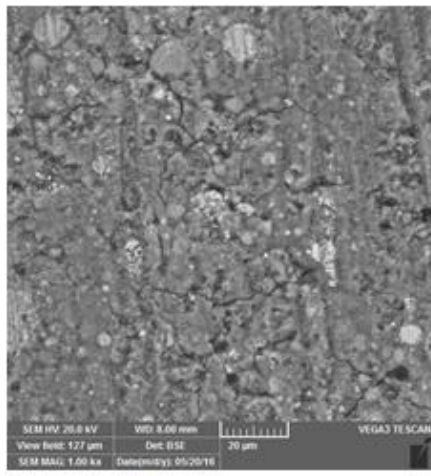

(a)

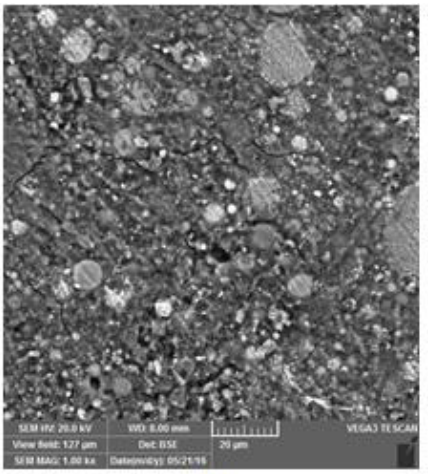

(b)

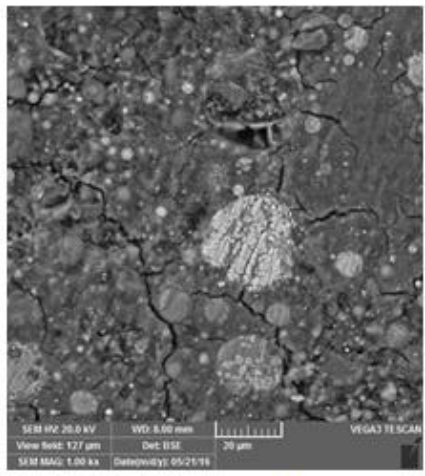

(c)

Fig. 5. SEM image of geopolymer with the addition of: (a) 5\%; (b) $10 \%$; and (c) $15 \%$ of RHA

Table 2 shows that the compressive strength of the sample contain 15\% RHA was declined. The highest compressive strength was 26. $21 \mathrm{MPa}$ obtained on the sample containing of $10 \%$ RHA. Nurfadilla [8] found that geopolymers made from FA have compressive strength about $23.4 \mathrm{MPa}$. The addition of RHA into geopolymer structure was found to increase the magnitude of compressive strength up to $10 \%$. The presence of RHA will increase $\mathrm{Si} / \mathrm{Al}$ molar ratio of the starting material, the density of Si-O-Si chain and improve the strength of geopolymers [13].

Table 2. 7 days compressive strength of hybrid composite RHA-geopolymers

\begin{tabular}{|c|c|}
\hline Sample & Compressive Strength (MPa) \\
\hline FA-ASP 5\% & 26.00 \\
\hline FA-ASP $10 \%$ & 26.21 \\
\hline FA-ASP $15 \%$ & 25.59 \\
\hline
\end{tabular}

Fig. 6a shows that one side of the sample was exposed to fire up to $1540^{\circ} \mathrm{C}$. The temperature of the sample was measured by using a thermocouple placed around $2 \mathrm{~cm}$ from the fire source for 30 minutes. It was observed that the sample did not burn, release smoke and showed significant physical damage after testing as shown in Figure 7(b).

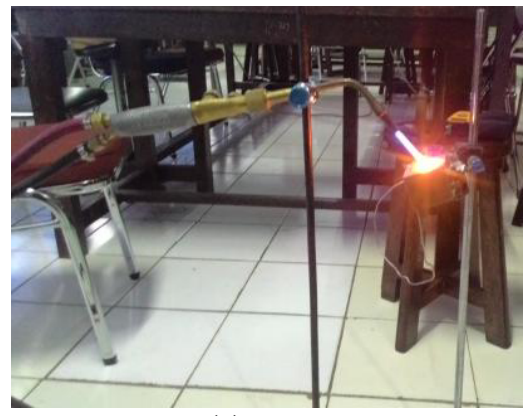

(a)

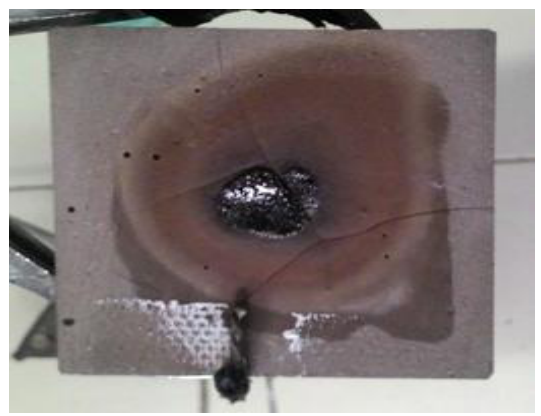

(b)

Fig. 6. (a) Fire resistance measurement (b) sample condition after measurement 
Fig. 7 shows the result fire resistance measurement of the resulting composites. The temperature different between fire source and $2 \mathrm{~cm}$ from the source reaching $1038^{\circ} \mathrm{C}$. This graph shows that these materials can be applied as heat and fire shielding materials including bricks as fire is the most devastating calamity in many buildings. The results of study was similar to those reported by Irfanita et. al. [14] who also found that geopolymers made from FA were able to resist fire up to $1000^{\circ} \mathrm{C}$. Kaloari et. al. [5] also investigated the potential of geopolymers as coating materials and the addition of RHA were able to increase the thermal properties of geopolymers.

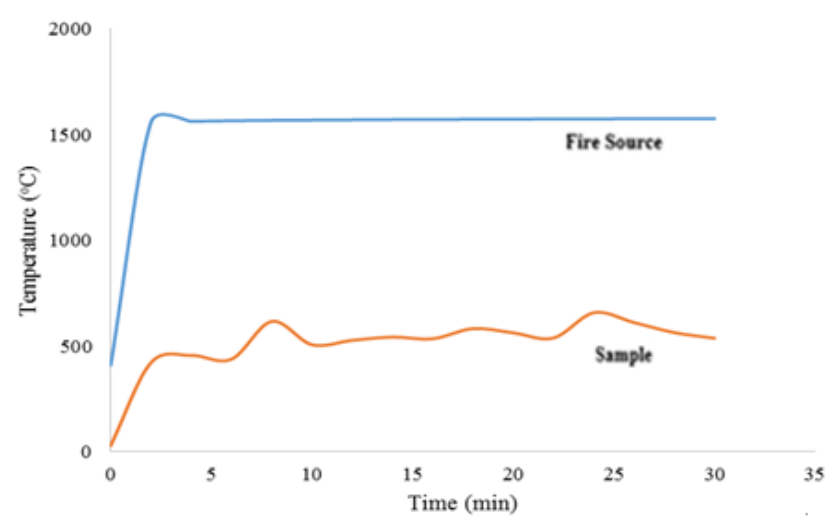

Fig. 7. The graph of temperature vs time for hybrid composite geopolymer containing $10 \%$ RHA

$1 \mathrm{M} \mathrm{H}_{2} \mathrm{SO}_{4}$ solution was used for acid resistance measurement. The samples were soaked in the solution for 4 days. Fig. 8 showed the appearance of the samples after 4 days in acid solution. It was observe the color change of the samples due to strong acid attack on the surface of the samples.

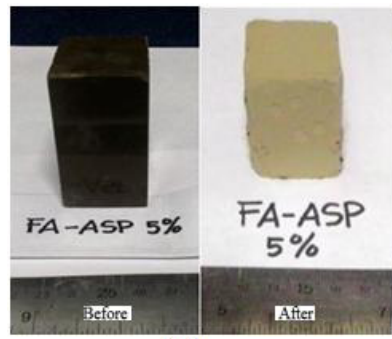

(a)

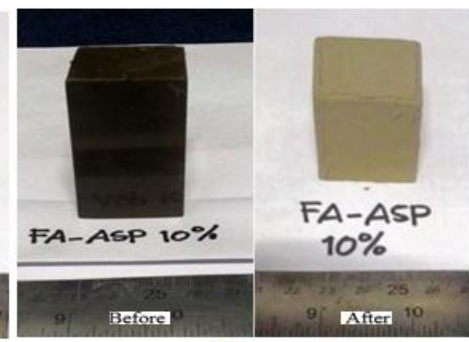

(b)

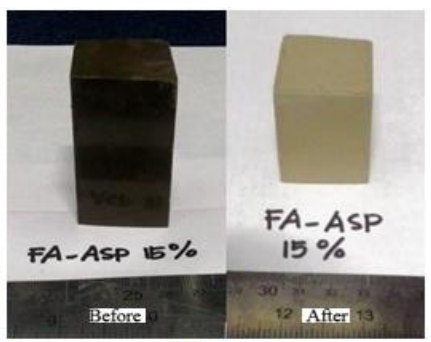

(c)

Fig. 8. The appearance of hybrid composite RHA-Geopolymer before and after 4 days acid attack

Table 3 shows the bulk density of the sample before and after 4 days in acid solution. It shows that the density of samples decreased. It indicates that the structural change in geopolymers network or the formation of new phases. Figure 9 is the cross section of the sample after acid attack showing the depth penetration of $\mathrm{H}_{2} \mathrm{SO}_{4}$ on the surface of the sample. The addition of RHA into geopolymers also improves the resistance of the material in high acidity [15]. 
Table 3. The density of hybrid composites RHA-geopolymer before and after acid attack

\begin{tabular}{|c|c|c|}
\hline \multirow{2}{*}{ Sample } & \multicolumn{2}{|c|}{ Density $\left(\mathbf{g} / \mathbf{c m}^{\mathbf{3}}\right)$} \\
\cline { 2 - 3 } & Before Acid Attack & After Acid Attack \\
\hline FA-ASP 5\% & 2.08 & 1.90 \\
\hline FA-ASP 10\% & 2.07 & 1.92 \\
\hline FA-ASP 15\% & 2.03 & 1.90 \\
\hline
\end{tabular}

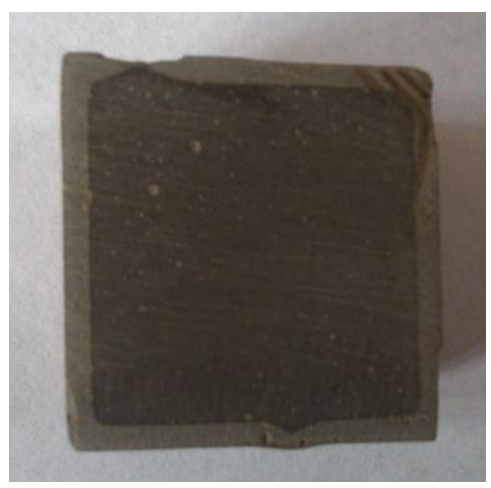

Fig. 9. The cross section of the sample after acid attack

Fig. 10 shows the diffraction patterns of hybrid composite RHA-geopolymer after acid attack test. It can be seen the formation of gypsum mineral due to the reaction between $\mathrm{H}_{2} \mathrm{SO}_{4}$ and $\mathrm{CaO}$ of fly ash. It was found that the composite with $15 \%$ showed the highest peak of gypsum phase. Composite contained 10\% RHA showed the lowest peak of gypsum phase indicating that this composition is the most resist composite in acid attack.

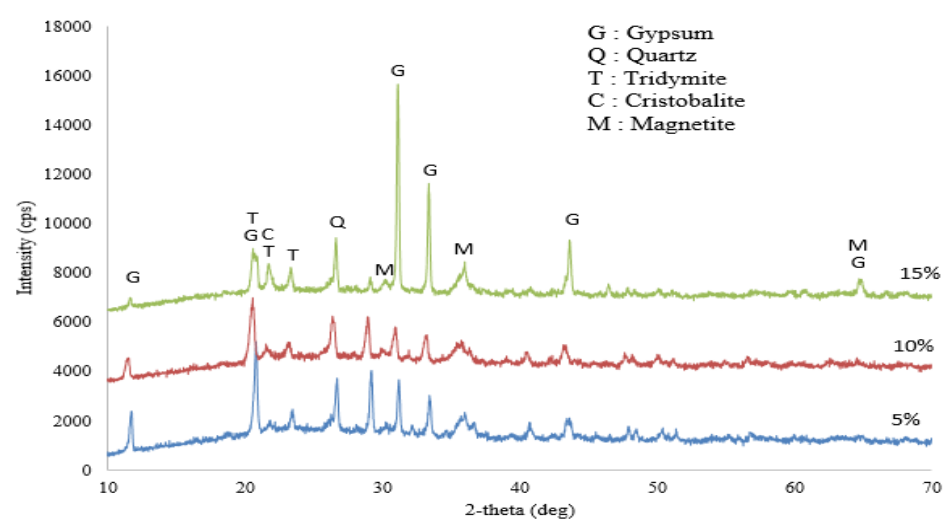

Fig. 10. The diffractogram of hybrid composite RHA-geopolymer contain of 5\%,10\%, and $15 \%$ RHA after 4 days acid attack

Figure 11 shows the morphology of the RHA-geopolymers with the addition of 5\% to $15 \%$ that has been soaked in $1 \mathrm{M} \mathrm{H}_{2} \mathrm{SO}_{4}$ solution for 4 days. The micrographs showed the different phases of the sample after acid attack. It can be seen the physical damage as well as the change of chemical composition of the area which were in contact with $\mathrm{H}_{2} \mathrm{SO}_{4}$. The x-ray diffraction results showed that the reaction between $\mathrm{H}_{2} \mathrm{SO}_{4}$ and $\mathrm{CaO}$ in fly ash formed gypsum $\left(\mathrm{CaSO}_{4}\left(\mathrm{H}_{2} \mathrm{O}\right)_{2}\right)$ minerals. It is well known that the presence of substantial gypsum 
minerals in the network of geopolymers will decrease its mechanical strength. This research finding suggest that hybrid composite RHA-geopolymer has a potential to be used as a raw material for bricks bearing building.

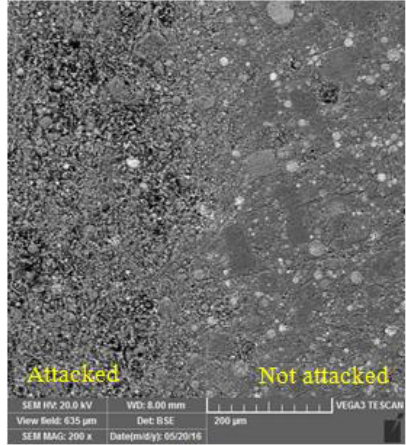

(a)

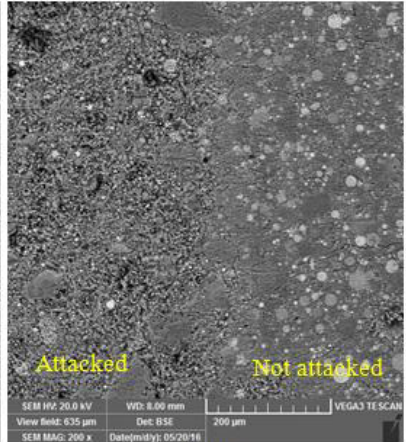

(b)

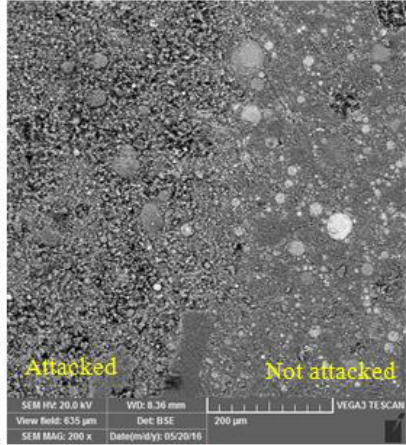

(c)

Fig. 11. SEM image of hybrid composite geopolymer with the addition of (a) 5\% RHA, (b) $10 \%$ RHA, and (c) $15 \%$ RHA after acid attacked

\section{Summary}

Hybrid composite rice husk ash (RHA)-geopolymers based on class-C fly ash has been synthesized through alkali activation method at $60^{\circ} \mathrm{C}$ for 1 hour. The addition of $10 \%$ RHA improved the compressive strength, fire and acid resistance of geopolymers. The results of this study suggest that hybrid composite RHA-geopolymers is suitable to be applied as material for bricks bearing building.

\section{References}

1. P. Turgut, J. Clean. Prod., 37, 361 (2012)

2. X. Guo, H. Shi, W.A. Dick, Cem. Concr. Compos., 32, 142 (2010)

3. L.N. Assi, E. Deaver, M.K. ElBatanouny, P. Ziehl, Constr. Build. Mater., 112, 807 (2016)

4. C.L. Hwang, T.P. Huynh, Constr. Build. Mater., 101, 1 (2015)

5. R.M. Kaloari, A. Haris, Mater. Sci. Forum., 841, 79 (2016)

6. Z. Pan, J.G. Sanjayan, Cem. Concr. Compos., 34, 261 (2012)

7. C.A. Jeyasehar, G. Saravanan, A.K. Ramakrishnan, S. Kandasamy, Asian J. Civ. Eng. BHRC., 14, 797 (2013)

8. Nurfadilla, M. Dzulkifli, F. Ramli, Mater. Sci. Forum. 841, 21 (2016)

9. V. Saraswathy, H.W. Song, Constr. Build. Mater., 21, 1779 (2007)

10. P. Chindaprasirt S. Rukzon, Constr. Build. Mater., 22, 1601 (2008)

11. C. Ferone, G. Roviello, F. Colangelo, R. Cioffi, O. Tarallo, Appl. Clay Sci., 73, 42 (2013)

12. M. Safiuddin, J.S. West, K.A. Soudki, Cem. Concr. Compos., 32, 708 (2010)

13. J. He, Y. Jie, J. Zhang, Y. Yu, G. Zhang, Cem. Concr. Compos., 37, 108 (2013)

14. R. Irfanita, A. Ansar, Subaer, Mater. Sci. Forum., 841 (2016)

15. Subaer, Pengantar Fisika Geopolimer. Makassar: BP Universitas Negeri Makassar, (2012) 